\title{
Effect of Women's Role on Household Decision Making on Institutional Delivery of the recent Child in Nepal
}

Ramesh Adhikari, PhD

Associate Professor, Geography and Population Department, Mahendra Ratna Campus, Tribhuvan University, Nepal

Email: rameshipsr@gmail.com

Accepted 15 June 2015

Nepalese women are behind than men in many areas, such as educational attainment, participation in decision-making and health service utilization, all of which have an impact on reproductive health outcomes. This paper explores effect of women's role on household decision making on institutional delivery of the child in Nepal Data as drawn from the Nepal Demographic and Health Survey, 2011. The analysis is confined to women who had given birth in the five years preceding the survey $(n=4,148)$. The net effect of women's role on household decision making on institutional delivery after controlling for the effect of other predictors has been measured through multivariate logistic regression analysis. The findings indicate that institutional delivery was still very low in Nepal. Only two in five of the women (40\%) had delivered their last child with health facilities. Notably, higher level of women's role on household decision was associated with higher level of institutional delivery [adjusted odds ratio $(a O R=1.20)$ ] than their comparison group. It can be concluded that programs should aim to increase use of maternal health services by improving women's role on household decision making so that the overall well-being of the family can be maintained and enhanced.

Key Words: women's role, household decision, institutional delivery, child

\section{Introduction}

Institutional delivery service utilization is one of the key and proven interventions to reduce maternal death. Despite various national and international efforts initiated to improve maternal health, about 289,000 women worldwide die each year as a result of complication arising from pregnancy and child birth (WHO et al., 2014). A substantial body of research has examined the role of women's autonomy on health and behavioral outcomes such as fertility (Abadian, 
1996), infant mortality (Adhikari \& Swangdee, 2010), and child rearing and pregnancy care (Matsumura \& Gubhaju, 2001; Mullany et al, 2005; Mistry et al, 2009).

Improving maternal health is one of the eight Millennium Development Goals (WHO, 2005). Research has shown that higher status for women correlates positively with their health and that of their children. According to estimates developed by the WHO, UNICEF, UNFPA and the World Bank, there were estimated 358,000 maternal deaths globally during 2008 (WHO, 2007; WHO, 2010). Nepal is making good progress on reaching most of the health MDGs. According to the latest UN data; Nepal has now met the MDG 5 target of reducing the maternal mortality ratio by $3 / 4$ by 2015 (WHO et al., 2012). Maternal mortality rate has reduced from 539 to 281 per 100,000 live births over the period of 1996 and 2006 (Pradhan et al. 1997; MoHP et al., 2012). Fertility has declined in Nepal over the last 2 decades from an average of 5.1 children per women in 1984-6 to the current level of 2.6 in 2011 (MoHP et al., 2012).

In many societies women's inferior social status and status within the household adversely affect their health and that of their children. The health of women and their children is largely impaired by culturally and socially determined roles for women through a complex web of physiological and behavioral interrelationships and synergies that permeate every aspect of their lives (Santow, 1995). Research has shown that higher status for women correlates positively with their health (Castle, 1993) and that of their children (Adhikari \& Sawangdee, 2011). A review study found positive associations between women's empowerment and lower fertility, longer birth interval and lower rates of unintended pregnancy (Upadhyay et al, 2014). Study also found that use of maternal health care services is influenced by women's roles in decision-making (Sado et al, 2014).

It is well documented that women almost everywhere are disadvantaged compared to men in terms of their access to assets, employment, health care, and education. Since the social status and level of autonomy of Nepali women is low, their status at the household level needs to be further explored in terms of health services utilization, which has a direct impact on maternal and infant morbidity and mortality. This relationship clearly warrants further attention, particularly in settings such as Nepal, where maternal and child health utilization is low (MoHP, 2002; MoHP et al., 2012).

This paper is an attempt to examine whether women's role on household decision making is associated with place of delivery of their child in the context of Nepal. We hypothesize that women with higher autonomy are more likely to deliver their recent child at health facilities than those with lower autonomy. This paper aims to close the knowledge gap in the literature with regard to a society in which women suffer gross disadvantages in the context of a patriarchal culture, which in turn can help guide reproductive health program planners and policy makers to understand various factors influencing maternal health service utilization and to assist in implementation of reproductive health programs that will decrease maternal morbidity and mortality. 
Effect of Women's Role on Household Decision Making on Institutional Delivery of the Recent Child

\section{Materials and methods}

\section{Data source}

Data for this paper was drawn from the Nepal Demographic and Health Survey, 2011. The primary purpose of the 2011 NDHS, a nationally representative sample survey, was to provide current and reliable data on fertility and family planning, child mortality, children's nutritional status, utilization of maternal and child health services, domestic violence, and knowledge of HIV/AIDS. The 2011 NDHS was carried out under the aegis of the Population Division of the Ministry of Health and Population.

\section{Sample size}

Interviews were completed for 12,674 women of reproductive age (MOHP, 2012). However, this analysis is confined to ever married women who had given at least one birth in the fiveyear preceding the survey $(n=4,148)$.

\section{Methods of data analysis}

Association between women's role on household decision making and institutional delivery of the recent child was assessed via bivariate analysis using chi-square tests. Then logistic regression was used to assess the net effect of women's role on institutional delivery after controlling for several other independent variables. Before the multivariate analysis, multicollinearity between the variables was assessed and the highly correlated variables were removed from the logistic model. It was found that the variables 'age of women' and 'total number of children ever born' was highly correlated. So the variable 'total number of children ever born' was not entered in the logistic regression model.

Two models were run in the analysis. The first model contained variables related to women's role on household decision making variable and dependent variable. In the second model, i.e. full model added the other socio-demographic and economic characteristics such as age of women, ethnicity, education, religion, ecological zone, place of residence, and wealth index.

\section{Variables}

\section{Dependent variable}

This paper has used place of delivery as a dependent variable. This variable is categorized into two categories and labeled as ' 0 'delivered of the recent child at home ' 1 ' institutional delivery (delivered at hospital, PHCC, HP, or SHP) '. 
Effect of Women's Role on Household Decision Making on Institutional Delivery of the Recent Child

\section{Independent variables}

Key explanatory variable of this paper was women's role on household decision-making autonomy. As other study (Adhikari and Swangdee, 2010) women's role on household decision-making, which was measured based on responses to "Who makes the following decisions in (respondent's) household about: 1) obtaining health care for yourself; 2) large household purchases; and 3) visits to family or relatives?" Response options were: a) respondent alone; b) respondent and husband/partner; c) respondent and other person; d) husband/partner alone; e) someone else; f) other. The value of 1 is assigned if the response was (a), (b), or (c), that is, involvement of the respondent, or else 0 , for no involvement of the respondent.

The other control variables included in this study were demographic and socioeconomic variables such as age, number of children born, ethnicity, education, religion, ecological zone, place of residence, and wealth status of households.

\section{Result}

About two-fifth of the ever married women who had given birth in the five years preceding the survey $(40 \%)$ were youth aged 15-24. More than a fifth of women had four or more children. A considerable proportion of these women (37\%) were from Janajati ethnic group followed by Brahmin/Chhetri (31\%). Only less than two in five women $(36 \%)$ had secondary or above education. An overwhelming majority of women believed Hindu religion (83\%), and lived in rural area $(90 \%)$.

Women's role on household decision was low in the country. Only less than two in five women (38\%) had any say in all three household decisions (Table 1). 
Effect of Women's Role on Household Decision Making on Institutional Delivery of the Recent Child

Table 1: Background characteristics of ever married women who had given at least one birth in the five-year preceding the survey

\begin{tabular}{lcc}
\hline Demographic and socio-economic characteristics & Percent & Number \\
\hline Age group & & \\
\hline Less than 25 years & 40.1 & 1662 \\
25-29 years & 31.6 & 1310 \\
30 years or above & 28.4 & 1176 \\
\hline Total number of children ever born & & \\
\hline One & 31.4 & 1302 \\
Two & 28.0 & 1162 \\
Three & 17.7 & 733 \\
Four or more & 22.9 & 952 \\
\hline Ethnicity & & \\
\hline Brahmin/Chhetri & 30.9 & 1283 \\
Janajati & 36.7 & 1523 \\
Dalit & 16.5 & 683 \\
Other & 15.9 & 660 \\
\hline Education level of women & & \\
\hline No education & 43.9 & 1822 \\
Primary & 20.1 & 835 \\
Secondary or above & 36.0 & 1492 \\
\hline Religion & & \\
\hline Hindu & 83.0 & 3444 \\
Buddhist & 8.7 & 360 \\
Muslim & 5.7 & 235 \\
Kirat/Christian & 2.6 & 109 \\
\hline Ecological zone & & \\
\hline Mountain & 7.4 \\
Hill & 40.2 & 306 \\
Terai & 52.4 & 1669 \\
\hline Place of residence & & 2174 \\
\hline Urban & 10.1 & \\
Rural & 89.9 & 318 \\
\hline Wealth index & & \\
\hline Poor & 45.3 & 1879 \\
Middle & 21.0 & 1397 \\
\hline Wich & 33.7 & 2576 \\
\hline Nomen's involved in all three household decisions & & \\
Has any say in all three household decisions & 62.1 & $\mathbf{4 1 4 8}$ \\
\hline Total & 37.9 & \\
\hline & $\mathbf{1 0 0 . 0}$ & \\
\hline & & \\
\hline
\end{tabular}


Effect of Women's Role on Household Decision Making on Institutional Delivery of the Recent Child

Only 40 percent of the married women had institutional delivery of the recent child. Women's role on household decision making was associated with institutional delivery. Institutional delivery was higher among those women who had any say in household decisions ( $43 \%$ vs. $39 \%$ ). In regard to socio-demographic variables, institutional delivery was lower among older, those who had more children, those who were illiterate, those who were from Dalit caste, those who lived in mountain region, lived in rural area and those who were poor (Table 2).

Table 2: Background characteristics of married women who had given at least one birth in the five-year preceding the survey by place of delivery for the most recent live birth

\begin{tabular}{|c|c|c|c|c|}
\hline & \multicolumn{2}{|c|}{ Place of delivery } & \multicolumn{2}{|c|}{ Total } \\
\hline & Home & Institution & $\%$ & $\mathbf{N}$ \\
\hline \multicolumn{5}{|l|}{ Women's role } \\
\hline Women's role on household decision making & \multicolumn{2}{|c|}{ * } & & \\
\hline Not involved in all three household decisions & 61.3 & 38.7 & 100 & 2576 \\
\hline Has any say in all three household decisions & 57.3 & 42.7 & 100 & 1573 \\
\hline \multicolumn{5}{|l|}{ Socio-demographic characteristics } \\
\hline Age group & \multicolumn{2}{|c|}{$* * *$} & & \\
\hline Less than 25 years & 53.7 & 46.3 & 100 & 1662 \\
\hline $25-29$ years & 58.6 & 41.4 & 100 & 1310 \\
\hline 30 years or above & 69.7 & 30.3 & 100 & 1176 \\
\hline Total number of children ever born & \multicolumn{2}{|c|}{$* * *$} & & \\
\hline One & 38.4 & 61.6 & 100 & 1302 \\
\hline Two & 58.7 & 41.3 & 100 & 1162 \\
\hline Three & 71.3 & 28.7 & 100 & 733 \\
\hline Four or more & 81.4 & 18.6 & 100 & 952 \\
\hline Ethnicity & \multicolumn{2}{|c|}{$* * *$} & & \\
\hline Brahmin/Chhetri & 50.6 & 49.4 & 100 & 1283 \\
\hline Janajati & 63.1 & 36.9 & 100 & 1523 \\
\hline Dalit & 68.8 & 31.2 & 100 & 683 \\
\hline Other & 60.7 & 39.3 & 100 & 660 \\
\hline Education level of women & \multicolumn{2}{|c|}{$* * *$} & & \\
\hline No education & 77.8 & 22.2 & 100 & 1822 \\
\hline Primary & 63.7 & 36.3 & 100 & 835 \\
\hline Secondary or above & 35.6 & 64.4 & 100 & 1492 \\
\hline Religion & \multicolumn{2}{|c|}{$* * *$} & & \\
\hline Hindu & 58.3 & 41.7 & 100 & 3444 \\
\hline Buddhist & 69.9 & 30.1 & 100 & 360 \\
\hline Muslim & 62.7 & 37.3 & 100 & 235 \\
\hline Kirat/Christian & 66.1 & 33.9 & 100 & 109 \\
\hline
\end{tabular}


Effect of Women's Role on Household Decision Making on Institutional Delivery of the Recent Child

Table 2: Continue

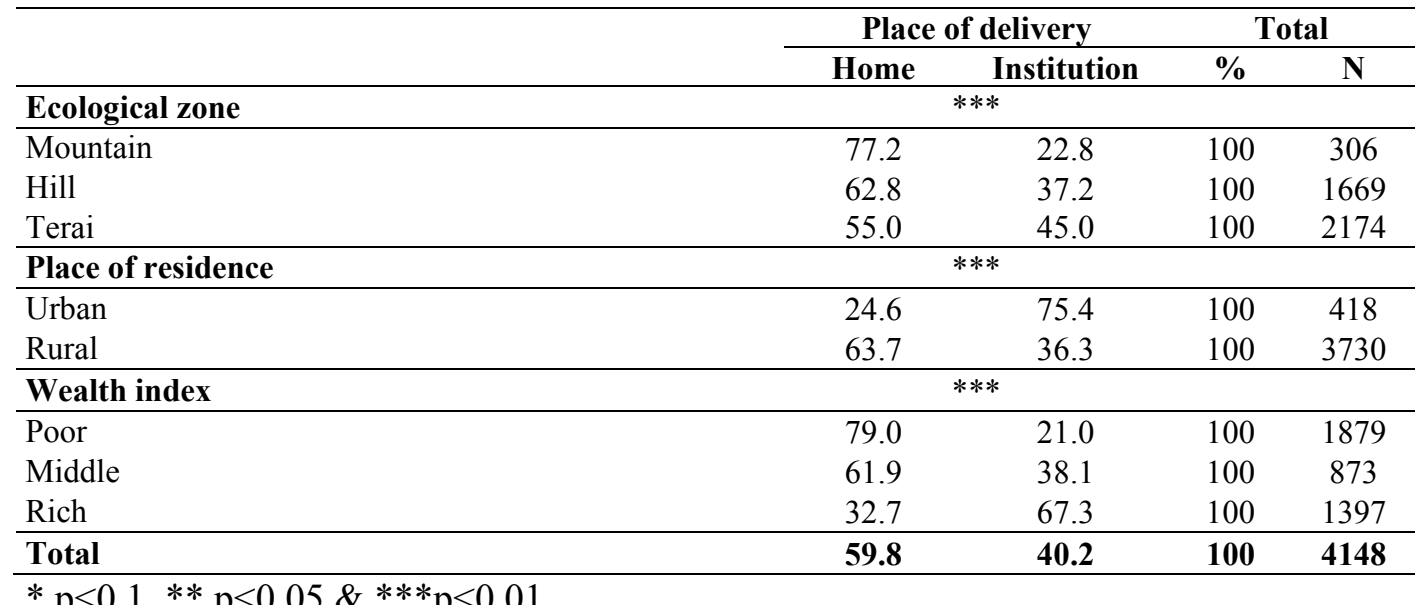

The multivariate analysis found that women's role on household decision making and other several variables were significantly associated with institutional delivery. The odds ratio shown in table 3 presents the effect of each independent variable on the dependent variable. Women's role on household decision making had resulted significantly higher institutional delivery $(\mathrm{aOR}=1.20)$ after controlling for other socio-demographic and economic variables.

The other control variables such as age, level of education, religion, place of residence and wealth index had significant association with place of delivery. Women's aged 25-29 $(\mathrm{aOR}=0.78)$ and 30 or above $(\mathrm{aOR}=0.67)$ were less likely to have institutional delivery compared with the youth mothers aged less than 25 years.

The study found that women with higher level education were more likely to have institutional delivery $(\mathrm{aOR}=1.7$ for Primary and $\mathrm{aOR}=3.5$ for secondary or above) to their recent child compared with illiterate women. Similarly, middle class and rich women were more likely to have institutional delivery of their child (aOR=1.68 and 3.49, respectively) compared with poor women. On the other hand, rural women were less likely to deliver their child at health facilities $(\mathrm{aOR}=0.35)$ compared with women in urban area (Table 3$)$. 
Effect of Women's Role on Household Decision Making on Institutional Delivery of the Recent Child

Table 3: Adjusted odds ratios (aOR) from multivariable logistic regression assessing the likelihood among women having institutional delivery within the past five years preceding the survey by women's role on household decision making and selected socio- demographic and economic predictors

\begin{tabular}{|c|c|c|}
\hline Predictors & Model I & Model II \\
\hline \multicolumn{3}{|l|}{ Women's role on household decision making } \\
\hline Not involved in all three household decisions & (ref.) & (ref.) \\
\hline Has any say in all three household decisions & $1.18^{* *}$ & $1.20 * *$ \\
\hline \multicolumn{3}{|l|}{ Socio-demographic predictors } \\
\hline \multicolumn{3}{|l|}{ Age group } \\
\hline Less than 25 years & & (ref.) \\
\hline $25-29$ years & & $0.78^{* *}$ \\
\hline 30 years or above & & $0.67 * * *$ \\
\hline \multicolumn{3}{|l|}{ Ethnicity } \\
\hline Brahmin/Chhetri & & (ref.) \\
\hline Janajati & & 0.85 \\
\hline Dalit & & 1.03 \\
\hline Other & & 0.93 \\
\hline \multicolumn{3}{|l|}{ Education level of women } \\
\hline No education & & (ref.) \\
\hline Primary & & $1.71 * * *$ \\
\hline Secondary or above & & $3.49 * * *$ \\
\hline \multicolumn{3}{|l|}{ Religion } \\
\hline Hindu & & (ref.) \\
\hline Buddhist & & 0.83 \\
\hline Muslim & & 1.36 \\
\hline Kirat/Christian & & 0.66 \\
\hline \multicolumn{3}{|l|}{ Ecological zone } \\
\hline Mountain & & (ref.) \\
\hline Hill & & 1.23 \\
\hline Terai & & 1.38 \\
\hline \multicolumn{3}{|l|}{ Place of residence } \\
\hline Urban & & (ref.) \\
\hline Rural & & $0.35 * * *$ \\
\hline \multicolumn{3}{|l|}{ Wealth index } \\
\hline Poor & & (ref.) \\
\hline Middle & & $1.68^{* * *}$ \\
\hline Rich & & $3.49^{* * *}$ \\
\hline Constant & $0.63^{* * *}$ & $0.51^{* *}$ \\
\hline-2 log likelihood & 5585.1 & 4544.9 \\
\hline Cox \& Snell R Square & 0.002 & 0.223 \\
\hline
\end{tabular}


Effect of Women's Role on Household Decision Making on Institutional Delivery of the Recent Child

\section{Discussion and conclusion}

This paper explores dimensions of women's role on household decision and their relationship to place of delivery of the recent child. Results show that both wormen's role on hosuehold decision and institutional delviery is low in Nepal. It also shows that higher level of women's role on household decision was positively associated with higher level of institutional delivery.

Bivariate analysis shows that variables such as women's role on household decision making is important variable in explaining institutional delivery. This study further found that age group of women, education level of women, place of residence and wealth index variables have an significant association with institutional delviery of the child. In the multivariate analysis women's reole on household decision making is significant predictors of haivng institutional delivery.

Study showed that institutional delviery is significantly higher among those women who were involved in decisions regarding their household activities compared to those who were not. This study is similar to the study that suggests use of maternal health care services is influenced by women's roles in decision-making (Sado et al, 2014). A possible explanation could be that women who have role on household decions making are more likely to have a higher level of autonomy on health care, which might lessen their reproductive behavior risks (Dyson, 1983). A study in India has also confirmed that a women's control over household resources (ability to keep money aside) has a significant positive effect on both the demand for prenatal care and the probability of hospital delivery (Maitra, 2004).

There are some limitations in the interpretation of the results of this study. Women's role is a complex phenomenon that cannot be completely measured by only a few household decision-making indicators. Similarly, as pointed out previously, we restricted our subjects to women who had given at least one birth in the five-year preceding the survey, so our results regarding institutional delivery should be generalized with care. Because the cross-sectional design of the study and all of the items analyzed in the logistic regression analysis came from information at the time of survey, the analysis can only provide evidence of statistical association between those items and institutional delivery and cannot show cause-effect relationships.

In conclusion women's role on household decion making is a strong predictor among many other predictors of institutional delivery of the recent child in Nepal. Women's decisionmaking power appear to be the most powerful predictors among many others for increasing institutional delivery. Hence, in order to increase institutional delivery, ongoing activities to empower women should be sustained and broadened to include every woman in order to reach the MDG goal for the year 2015. The study results also suggest that policy actions that increase women's role in household decision making could be effective in helping assure institutional delivery. If programs focus on increasing women's role on decision making, institutional delivery will increase and the overall well being of the family will be maintained and be enhanced. 
Effect of Women's Role on Household Decision Making on Institutional Delivery of the Recent Child

\section{Acknowledgments}

The author thanks MEASURE DHS + for providing access to the data.

\section{References}

Abadian, S. (1996). Women's autonomy and its impact on fertility. World Development, 24(12): 1793-1809.

Adhikari, R. \& Sawangdee, Y. (2011). Influence of women's autonomy on infant mortality in Nepal, Reproductive Health, 8(7). Retrieved on January 15, 2015 from http://www.biomedcentral.com/content/pdf/1742-4755-8-7.pdf

Castle S.E. (1993). Intra-household differentials in women's status: household function and focus as determinants of children's illness management and care in Rural Mali. Health Transition Review, 3(2), 137-157.

Dyson, T. \& Moore, M. (1983). On kinship structure, female autonomy, and demographic behavior in India. Population and Development Review, 9(1), 35-60.

Maitra, P. (2004). Parental bargaining, health inputs and child mortality in India. Journal of Health Economics, 23, 259-291.

Matsumura, M. \& Gubhaju, B. (2001). Women's status, household structure and utilization of maternal health services in Nepal. Asia Pacific Population Journal, 16 (1), 23-43

Ministry of Health [Nepal], New Era, and ORC Macro. (2002). Nepal demographic and health survey 2001. Calverton, Maryland, USA: Ministry of Health; New Era and ORC Macro.

Ministry of Health and Population (MOHP) [Nepal], New ERA, and ICF International Inc. (2012), Nepal demographic and health survey 2011. Calverton, Maryland: Ministry of Health and Population (MOHP) [Nepal], New ERA, and ICF International Inc.

Mistry, R, Galal \& Lu, M. (2009). Women's autonomy and pregnancy care in rural India: A contextual analysis. Social Science and Medicine, 69, 926-933.

Mullany, B. C., Hindin, M. J. \& Becker. S. (2005). Can women's autonomy impede male involvement in pregnancy health in Kathmandu Nepal. Social Science and Medicine, 61 (9), 1993-2006.

Santow, G. (1995). Gender differences in health and risks and use of services. Proceedings of the United Nations expert group meeting on Population and Women, 22-26 June 1992. 31-36, New York: United Nations.

Singh, S. \& Darroch, J. E. (2012). Adding it up: Cost and benefits of contraceptive servicesestimates for 2012. New York: Guttmacher Institute.

UNFPA. (2012). Maternal deaths halved in 20 years, but faster progress needed. Retrieved on June, 2014 from http://www.unfpa.org/public/home/news/pid/10730 
Effect of Women's Role on Household Decision Making on Institutional Delivery of the Recent Child

Upadhyay U. D., Gipson J. D., Withers, M., Lewis, S., Ciaraldi, E. J., Fraser, A., Huchko, M. J., Prata, N. (2014). Women's empowerment and fertility: A review of the literature. Social Science and Medicine, 115,111-120.

WHO, UNICEF, UNFPA and The World Bank. (2010).Trends in Maternal Mortality: 1990 to 2008. Geneva: World Health Organization.

WHO, UNICEF, UNFPA, The Work Bank \& UN Population Division. (2014). Trends in maternal mortality: 1990 to 2013. Geneva: WHO. Retrieved on 18 January, 2015 from http://apps.who.int/iris/bitstream/10665/112682/2/9789241507226_eng.pdf

WHO. (2004). Unsafe abortion: Global and regional estimates of the incidence of unsafe abortion and associated mortality in 2004. Geneva: WHO . (2005). Health and millennium development goals. Geneva: WHO. . (2007). Maternal mortality in 2005. Geneva: WHO, UNICEF, UNFPA \& The World Bank. Geneva . (2012). Safe abortion: technical and policy guidance for health system. Geneva: WHO.

WHO/SEARO. (2001). Making pregnancy safer. New Delhi: WHO/SEARO. 